\title{
Presença de violonistas espanhóis em São Paulo no século XIX
}

\section{Flavia Prando}

\author{
Universidade de São Paulo / SESC | Brasil
}

\begin{abstract}
Resumo: $\mathrm{O}$ presente artigo versa sobre a presença de violonistas na cidade de São Paulo no século XIX. Através de críticas do pianista Alexandre Levy, publicadas em 1890, analisam-se os concertos de Martinez Toboso e Gil-Orozco, violonistas espanhóis, cujo duo parece ter sido o primeiro a realizar concertos mais formais em São Paulo. Trata, ainda, da atuação de Gil-Orozco, que fixou residência na capital paulistana durante dezessete anos (1890-1907), tendo sido fundamental para o desenvolvimento do violão na cidade.
\end{abstract}

Palavras-chave: Violão no século XIX, Violão em São Paulo, Martinez Toboso, Gil-Orozco, Alexandre Levy.

\begin{abstract}
This article discusses the actuation of guitarists in São Paulo's city in the 19th century. Through reviews written by the pianist Alexandre Levy, published in 1890, it analyses the concerts of Martinez Toboso and Gil-Orozco, Spanish guitarists, whose duo appears to have been the first to realize formal concerts in São Paulo. This article also investigates Gil-Orozco's presence in the city, since he lived for seventeen years in São Paulo (1890-1907), being essential for the guitar's development in the city.
\end{abstract}

Keywords: Guitar in the 19th century. Guitar in São Paulo's city, Martinez Toboso, Gil-Orozco, Alexandre Levy. 


\section{1 atividade violonística do século XIX no Brasil não é muito conhecida. Com exceção de Heitor Villa-Lobos (1887-1959), ainda são poucos os estudos dedicados à análise da produção para violão anterior à primeira metade do século XX, tanto de compositores} nascidos quanto radicados no Brasil (AMORIM, 2018, p. 43). Se esta é uma realidade no Rio de Janeiro, antiga capital federal do país, onde as condiçôes políticas, geográficas e históricas favoreceram o desenvolvimento e o registro das práticas e fluxos culturais, em outras localidades do país esta situação é ainda mais patente. No entanto, com o crescimento das hemerotecas digitais, este conhecimento tornou-se mais acessível, fazendo emergir práticas musicais que apontam para uma produção e uma circulação que a historiografia sobre o instrumento julgava só ter sido alcançada nas primeiras décadas do século XX. Por outro lado, a abertura de acervos particulares à consulta pública ${ }^{1}$ possibilita o rastreamento de algo da produção apontada pelos periódicos do século XIX. A digitalização, catalogação e disponibilização dos acervos em ambientes virtuais serão inevitáveis, e alargarão ainda mais as possibilidades de recompor pedaços do grande mosaico de sonoridades do violão brasileiro. Trata-se, portanto, de um novo momento para a historiografia sobre o instrumento, de uma verdadeira reconstrução da musicologia do violão.

Cabe ressaltar que importantes trabalhos de pesquisa sobre o violão na cidade foram realizados antes do advento das hemerotecas digitais e/ou da abertura para consulta pública de diversos acervos particulares $^{2}$. No caso específico de São Paulo, mencionamos as pesquisas de mestrado e doutorado do professor Giacomo Bartoloni (UNESP). No mestrado (1995), Bartoloni fez um levantamento bibliográfico de informações sobre a prática do instrumento em São Paulo, por meio de jornais e revistas especializadas. Apresentou ainda uma listagem de obras significativas do período analisado. No doutorado (2000), Giacomo Bartoloni estudou o violão em São Paulo com enfoque na história social do instrumento. O autor comparou as técnicas de composição para piano com as técnicas de

\footnotetext{
${ }^{1}$ Citamos, como exemplo, a Coleção Ronoel Simốes. Ronoel Simões (1919 - 2010) foi um violonista, pesquisador e colecionador paulista. Seu acervo, construído ao longo de sessenta anos, é um dos maiores acervos de partituras e gravaçóes de violão dedilhado do mundo e foi adquirido pela prefeitura de São Paulo em 2010. No ano de 2016, a Discoteca Oneyda Alvarenga, situada no Centro Cultural São Paulo, disponibilizou o acervo ao público. Dentre os itens desta coleção, existem gravaçóes, fotos, recortes de jornal, cartas, partituras manuscritas e editadas. Estáo representados os grandes e médios violonistas, uma vez que Simóes não fazia juízo de valor, tendo colecionado tudo que se referisse ao violão dedilhado. Neste sentido, seu acervo possibilita traçar um panorama bastante alargado do instrumento, não somente dos cânones. Apresenta-se, assim, como uma potente fonte de possibilidades de reconstrução das práticas, repertórios e trajetórias do violão em diversos momentos e localidades.

${ }^{2}$ Além da Coleção Ronoel Simões, mencionamos as coleções de Jacob do Bandolim e Almirante, pertencentes ao acervo do Museu da Imagem e do Som (RJ), que abrigam uma quantidade considerável de obras para violão.
} 
composição para violão, mostrando que elas se influenciaram mutuamente. Outro trabalho fundamental é a dissertação de mestrado de Gilson Antunes (2002), sobre Américo Jacomino, o Canhoto. É uma pesquisa pioneira e referencial, não somente sobre Canhoto, mas especificamente sobre o movimento do violão na cidade de São Paulo nas duas primeiras décadas do século XX, disponibilizando dados sobre repertório, gravação e circulação do violão na cidade. Deve-se, ainda, a Paulo Castagna, Gilson Antunes e Eduardo Fleury, uma pesquisa pioneira, realizada em periódicos paulistanos, no início da década de 1990. Os três pesquisadores selecionaram as notícias sobre violão nas três primeiras décadas do século XX. Trata-se de um trabalho de fôlego, em três tomos, que tem servido de base para diversos artigos e pesquisas desde então ${ }^{3}$. Citamos também os trabalhos de Maurício Orosco (2001) e Paola Picherzky (2004), que trouxeram à luz os personagens de Isaías Savio e Armando Neves, respectivamente, abordando a obra e a atuação destes músicos. Estas são algumas das pesquisas que lançaram as bases sobre as quais o campo pode se expandir.

As novas descobertas acerca das práticas musicais no século $\mathrm{XIX}^{4}$ apontam para o cultivo do instrumento em saraus e apresentações públicas, dividindo espaço e repertório - majoritariamente, transcriçốes de trechos de óperas e danças de salão estilizadas (valsas, mazurcas e gavotas) - com outros instrumentos, como flauta, violino e piano. O violão, portanto, estava presente em diversos contextos burgueses e aristocratas. Percebem-se, ainda, evidências que assinalam uma difusão transversal do instrumento na sociedade brasileira no século XIX, revelando sua presença nas diversas manifestações culturais, em suas diferentes vertentes. Fica explícito que o cultivo do instrumento por música $a^{5}$ não era inexistente nesse período, conforme poderíamos supor anteriormente. Se não havia, como não existe ainda hoje, um mercado consolidado de partituras impressas para violão no Brasil, a quantidade de obras manuscritas encontradas recentemente em acervos, nos permite afirmar que havia a circulação de obras escritas para o instrumento. No caso de São Paulo, foco da atenção do presente artigo, as informações apontam para a disseminação do violão de concerto ainda no século XIX.

\footnotetext{
${ }^{3} \mathrm{~A}$ pesquisa não está publicada, mas ela é facilmente acessada devido à generosidade dos pesquisadores.

${ }^{4}$ Humberto Amorim, violonista, pesquisador e professor (UFRJ), localizou, recentemente (2019), o mais antigo periódico sobre o instrumento, O Guitarrista Moderno (1857). Além disto, encontrou diversas obras para violão compostas no século XIX, por violonistas como Alfredo Imenes e Melchior Cortez.

${ }^{5}$ Expressão que se refere a tocar músicas lendo partituras, em oposição ao aprendizado oral ou aural.
} 
No presente artigo, iremos tratar da presença de dois violonistas espanhóis em São Paulo no século XIX. Embora tenha havido notícias na imprensa paulistana sobre apresentações de violão a partir de meados do século XIX, o duo formado pelos valencianos José Martinez Toboso e Praxedes Gil-Orozco parece ter sido o primeiro a realizar concertos mais formais na cidade. O compositor Alexandre Levy registrou a atuação dos violonistas em dois textos publicados no jornal Correio Paulistano (1890). Ao que tudo indica, estas foram as primeiras críticas sobre concertos de violão publicadas na imprensa paulistana. Trataremos ainda da atuação de Gil-Orozco, que fixou residência na capital paulistana durante dezessete anos (1890-1907), sua presença parece ter sido fundamental para o desenvolvimento do violão na cidade.

\section{Os violonistas espanhóis José Martinez Toboso e Gil-Orozco}

José Martinez Toboso ${ }^{6}$ fez parte do grupo de violonistas ligados diretamente ao espanhol Julian Arcas (1832-1882) ${ }^{7}$, compositor e professor andaluz que antecedeu e influenciou Francisco Tárrega (1852-1909) e Antonio Torres (1817-1892) ${ }^{8}$. Em 1876, dedicou um recital às obras de Arcas na cidade espanhola de Sevilha. No mesmo ano, Antonio Torres construiu para ele o violão de onze cordas, que foi seu instrumento por toda a vida. Em 1878, apresentou-se em duo com Juan Parga (1843-1899), discípulo de Julian Arcas, e, em 1882, realizou uma turnê pela Espanha e Portugal com o violonista José Rojo, um jovem de quinze anos, discípulo de Juan Parga (PRAT, 1934, p. 196). Dois anos depois, formou dupla com outro discípulo de Arcas, o violonista Luis Soria (1851-1935). Portanto, Toboso

\footnotetext{
${ }^{6}$ As informaçôes biográficas aqui descritas acerca de Martinez Toboso foram retiradas de: HERRERA, Francisco. Enciclopedia de la Guitarra, segunda edición corregida y aumentada. Valencia: Editorial Piles, 2011, e TORRES, Norberto. La guitarra en la prensa de Sevilla y Almería en las dos épocas de Julián Arcas y Antonio de Torres. Sinfonia Virtual: Revista de Música Clásica y Reflexión Musical, n. 36, p. 1-43, 2019.

${ }^{7}$ Discípulo de José Asencio, por sua vez aluno do lendário violonista espanhol Dionísio Aguado (1784 - 1849), cujo método oitocentista foi bastante utilizado no Brasil, sobretudo na primeira metade do século XX. Atribui-se a Arcas o mérito de haver aconselhado Antonio Torres a ampliar o formato da caixa do instrumento (PRAT, 1934, p.33).

${ }^{8}$ Com o advento do piano e dos teatros no período Romântico, o violáo passou a ocupar um papel secundário, sobretudo em razão do baixo volume sonoro. O instrumentista e compositor espanhol Francisco de Assis Tárrega Eixea foi personagem central no renascimento do violão no séc. $\mathrm{XX}$, sendo considerado um dos fundadores do violão moderno. Embora Tárrega não tenha deixado nenhum método publicado, seus numerosos alunos disseminaram seus preceitos pelo mundo, sendo que muitos deles escreveram métodos baseados em seus ensinamentos, que viriam a ser denominados de Escola de Tárrega. Ele transcreveu obras do piano para o violáo, compôs, realizou recitais, lecionou e impulsionou a disseminação do violão moderno, cujo construtor mais emblemático foi o luthier espanhol Antonio Torres (1817-1892). O violão moderno possui uma caixa harmônica maior do que o violão romântico, e um sistema de leques interno que possibilitou melhor projeção do som, permitindo que o instrumento fosse executado em salas maiores.
} 
participou do grupo de instrumentistas, construtores e professores interessados em recolocar o violão em evidência através da expansão da sonoridade, do repertório e da técnica instrumental.

Em princípios de 1888, passou a se apresentar em duo com o concertista Gil-Orozco (18581916), com quem realizou uma série de concertos pela América Latina. Em 1890, continuou seu giro solitário pelo continente americano, pois Gil-Orozco, conforme veremos, decidiu residir em São Paulo?.

Toboso retornou ao Brasil no início do século XX, quando se apresentou no Rio de Janeiro e em São Paulo (1904), como integrante do Terceto Espanhol, com o bandurrista Primo Campos e o alaudista Daniel Avillar. Nessa ocasião, um jornal paulistano publicou: “infelizmente o notável guitarrista, que tanto renome deixou aqui, está hoje, por motivo de moléstia, reduzido a só poder acompanhar seus companheiros"10. A notícia evidencia que o reconhecimento conquistado pelo artista, em fins do século XIX, ainda ecoava no início do XX na imprensa paulista. Conhecemos apenas uma composição de Toboso: Viva la Pilarica, que apresenta o subtítulo de Gran Jota Aragonesa, editada pela Casa Dotesio, em Madrid (1911).

Em fins de novembro de 1900, o concertista participou, com Francisco Tárrega e Gil-Orozco, de duas apresentações em Requena, Valencia (Figuras 1 e 2). Requena era a cidade natal de GilOrozco, que, por motivos familiares, havia retornado à Espanha entre os anos de 1899 e 1901 (RODA, 2011, p. 165). Suspeitamos que Toboso e Gil-Orozco tenham sido os primeiros violonistas a trazer para São Paulo os princípios da Escola de Tárrega, quase três décadas antes da chegada de

\footnotetext{
${ }^{9}$ A historiografia disponível sobre o violão acusa a chegada de Gil-Orozco à cidade entre 1901 e 1903, baseada, sobretudo, nos depoimentos de Isaias Savio e Ronoel Simões para a revista Violão e Mestres (publicação da fábrica de violóes Tranquilo Giannini, entre 1964 e 1967), conforme veremos ao longo do presente texto. A revista registrou o movimento do violão na década de 1960 e publicou diversos textos referentes à história do violão, não somente brasileiro. Trata-se de uma publicação importantíssima para a memória do instrumento, tendo sido fonte para diversas pesquisas realizadas sobre violão no país. A história local do instrumento deve ter sido passada aos dois violonistas por testemunhos orais, uma vez que o violonista uruguaio chegou ao Brasil apenas na década de 1930 e Ronoel Simóes começou sua trajetória com o violão na década de 1940. A relação entre história e memória na construção da historiografia é um constante desafio teórico com o qual nos deparamos a todo momento. Ver mais em RICOEUR, Paul. A memória, a bistória, o esquecimento. Trad. Alain François. Campinas: Editora da Unicamp, 2007.

${ }^{10}$ O Commercio de S. Paulo, São Paulo, ano XII, n. 3649, p. 4, 01 mai. 1904.
} 
Josefina Robledo (1917) ${ }^{11}$, uma vez que a proximidade deles com o círculo de Julian Arcas (Juan Parga, José Rojo, Luis Soria), Antonio Torres e Francisco Tárrega nos faz crer que eles estivessem participando do desenvolvimento do violão moderno e das novas técnicas de execução que este instrumento passou a exigir.

FIGURA 1 - Capa dos concertos realizados na pequena cidade de Requena, por Tárrega, Toboso e Gil-Orozco, em 1900.

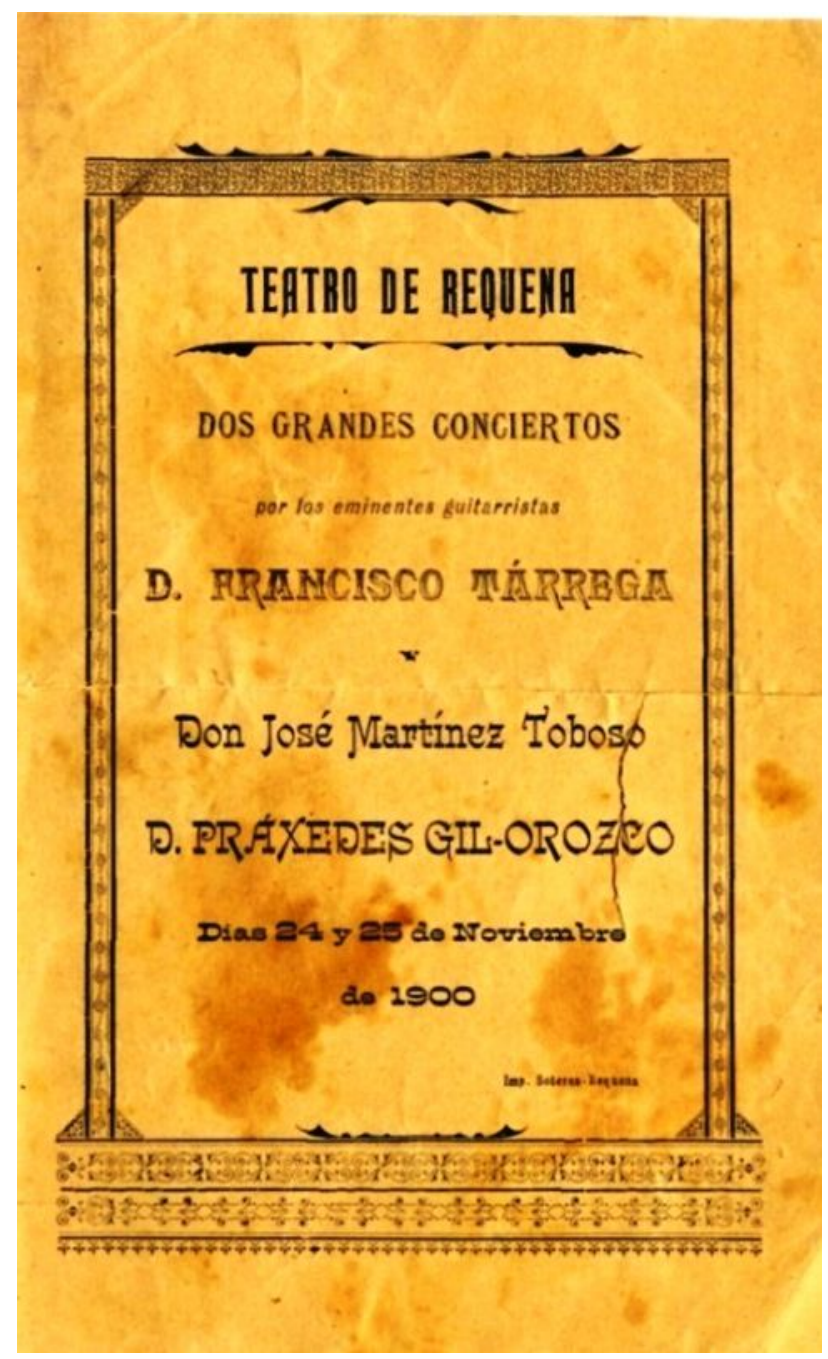

Fonte: RODA (2011, p. 171)

\footnotetext{
${ }^{11}$ Josefina Robledo (1892-1972) foi discípula de Francisco Tarrega. Em 1914, iniciou turnês de concertos pela Argentina, Uruguai, Paraguai e Brasil. Fixou residência na América do Sul por uma década, primeiro na Argentina e depois no Brasil. Não encontramos referências exatas das datas em que Josefina residiu em São Paulo, mas as notícias dos periódicos nos levam a crer que seja entre 1917 e 1919. Em 1924, a violonista retornou para a Espanha. O mais conhecido aluno de Josefina Robledo em São Paulo foi o paulista Oswaldo Soares, que publicou o método de violão $A$ Escola de Tarrega, Método Completo de Violão (1932). Ver mais sobre a violonista em: GONÇALVES, Leandro Márcio. Oprocesso de difusão do violão clássico no Brasil através da "Escola de Tárrega" entre 1916 e 1960. Dissertação de Mestrado. Universidade de Évora. Évora, 2015.
} 
FIGURA 2 - Programa dos concertos realizados na pequena cidade de Requena, por Tárrega, Toboso e Gil-Orozco, em 1900.

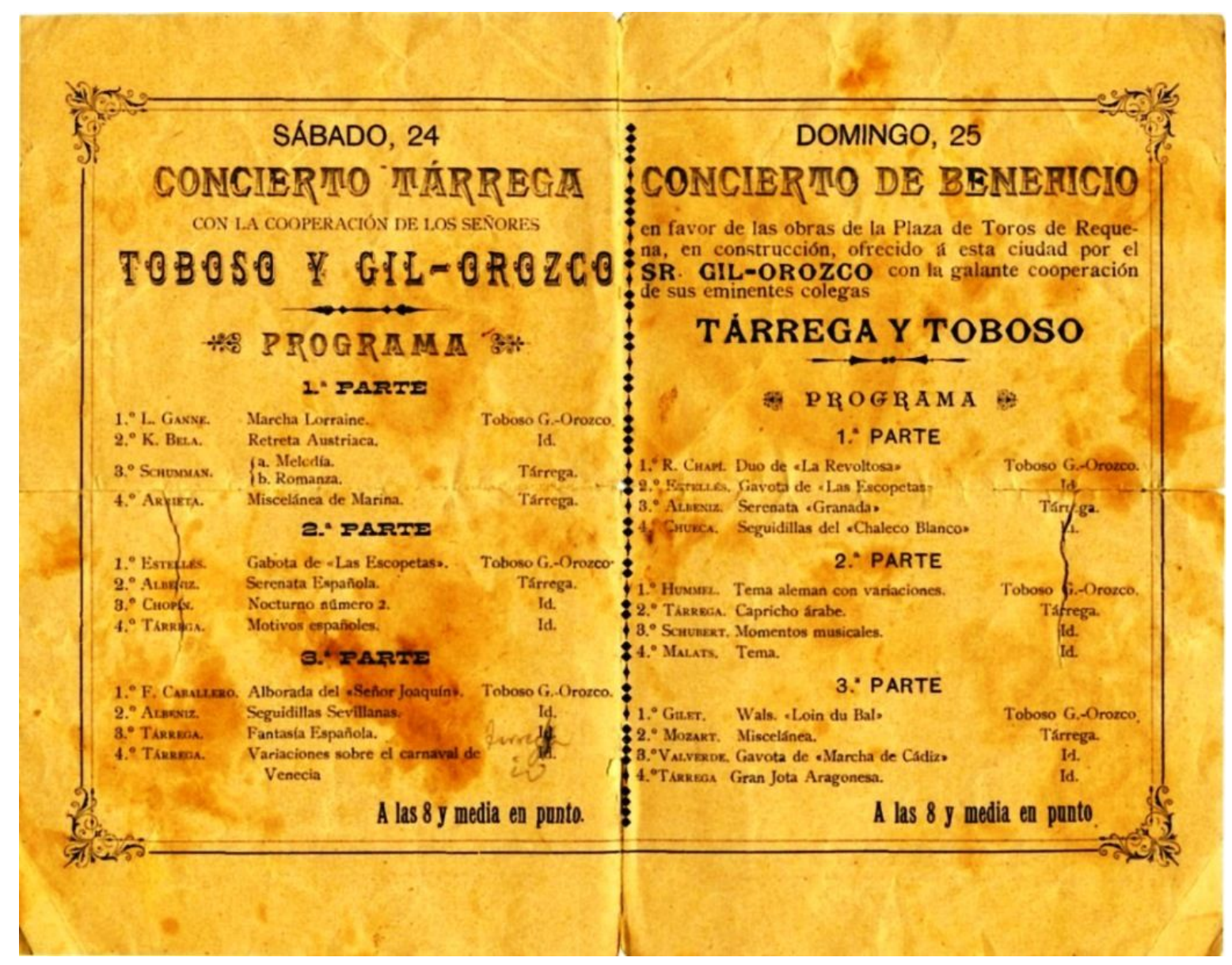

Fonte: RODA (2011, p. 172-173)

\subsection{Gil-Orozco e o violão em São Paulo}

Em 1889, Gil-Orozco e Martinez Toboso embarcaram rumo à América latina e realizaram uma série de concertos em diversos países, notadamente na Venezuela, Barbados, Trinidad y Tobago e Brasil (RODA, 2011, p. 81-93). No Brasil, chegaram em meados de 1889. Há farta documentação em periódicos locais sobre a passagem do duo por vários estados: Rio de Janeiro, Pará, Maranhão, Fortaleza, Recife, São Paulo, Santa Catarina, Rio Grande do Sul, Bahia e Minas Gerais. Em São Paulo, fizeram duas séries de concertos. A primeira foi em junho de 1890, conforme veremos nos textos de 
Alexandre Levy. Retornaram à cidade em novembro/dezembro do mesmo ano ${ }^{12}$, desta vez apresentando-se em trio com a violinista Giulietta Dionesi ${ }^{13}$.

No final de 1890, Toboso partiu para Argentina, tendo retornado logo em seguida para a Espanha, e Gil-Orozco fixou residência em São Paulo, inserindo-se na comunidade de imigrantes espanhóis. Em 1892, foi um dos fundadores do diário La Iberia, periódico em espanhol para a colônia de imigrantes residentes na cidade. Em 1896, apareceu como sócio fundador do Orfeón Español de São Paulo; e, em 1898, da Sociedade Espanhola de Socorros Mútuos São Paulo, entidades associativas que visavam dar suporte aos imigrantes espanhóis (RODA, 2011, p. 143-144). Envolveu-se, ainda, na campanha para coletar fundos para a guerra hispano-americana em $\mathrm{Cuba}^{14}$. Provavelmente, por esta razão, o violonista espanhol tenha ficado conhecido na historiografia brasileira sobre o instrumento como sendo de nacionalidade cubana ${ }^{15}$.

Gil-Orozco foi fundamental para a história do instrumento em São Paulo. Foi importador de instrumentos (1901), representando a fábrica de violóes de Pascual Roch \& Cia, com sede em Valencia, na Espanha. Os violóes eram expostos na Casa Bevilacqua ${ }^{16}$. É possível que tenha sido também responsável pela disseminação do Método Moderno para Guitarra, do mesmo Pascual Roch, método inspirado nos ensinamentos de Francisco Tárrega, de quem Roch foi discípulo, o que seria mais um indício da introdução dos ensinamentos do mestre catalão nesse princípio de século. GilOrozco ficou ainda conhecido na história do instrumento como o primeiro violonista a realizar concertos de violão solo na cidade (1904), quando teria executado "obras clássicas, zarzuelas espanholas e uma Fantasia Original, de sua própria autoria" ${ }^{17}$. O concerto teria ocorrido no Teatro

\footnotetext{
${ }^{12}$ Foi também Alexandre Levy quem escreveu sobre este concerto. Discorreu sobre as performances e repertório de Dionesi, Toboso e Gil-Orozco e ainda sobre a participação de uma pianista, a senhorita Imbert, cujo desempenho desagradou bastante ao crítico. Correio Paulistano, São Paulo, ano XXXVII, ed. 10256, p. 1, 09 nov. 1890.

${ }^{13}$ Jovem violinista italiana, apresentou-se aos 11 anos no Teatro Sant'Anna, no Rio de Janeiro (1889). Foi nesta apresentação que Dom Pedro II sofreu atentado de um republicano radical ao sair do concerto da violinista - quatro meses antes da proclamação da República. Nasceu em Livorno (c. 1877) e faleceu em Ouro Preto (1911). Cruz e Sousa dedicou a ela o poema "Giulietta Dionesi" (Publicado no livro póstumo "O Derradeiro"). Mais informaçóes em: http://karlaarmani.blogspot.com/search?q=Giulietta. Acesso em 11 de set. de 2019.

${ }^{14}$ Guerra ocorrida em 1898, entre a Espanha e os Estados Unidos, resultado da intervenção norte-americana na Guerra de Independência de Cuba.

${ }^{15}$ A primeira referência encontrada sobre a nacionalidade de Gil-Orozco foi escrita pelo violonista uruguaio Isaias Savio em: Violão e Mestres. São Paulo: Giannini S.A., ano II, no 9, p. 51, 1968. Salienta-se também a grafia do sobrenome: GilOrozco passou a ser referido nos periódicos, em grande parte das vezes, somente por Orosco ou Orozco.

${ }^{16}$ Jornal O Commercio de São Paulo, São Paulo, ano VIII, n. 2310, p. 3, 24 ago. 1901.

${ }^{17}$ Revista Violão e Mestres, São Paulo, ano II, n.o 07, p. 25, 1967. Não foram localizadas informaçóes sobre este concerto nos periódicos em circulação na cidade neste ano.
} 


\section{Santana.}

Em 1903, Gil-Orozco foi sócio proprietário de uma fábrica de cordas, A Torcedora Valenciana de Orosco E̊ Blanes, no bairro paulistano da Mooca (RODA, 2011, p. 145). A fábrica confeccionava cordas feitas de cânhamo ${ }^{18}$, linho ou juta da índia, de todos os tipos, trançadas, extra filadas e de todos os diâmetros e calibres. Eram vendidas na cidade, no interior e ainda exportadas para os estados do Rio de Janeiro, Bahia, Paraná, Santa Catarina, Rio Grande do Sul e Minas Gerais ${ }^{19}$. Os dois violonistas espanhóis certamente encontraram dificuldades para obter encordoamentos para seus violóes nas apresentações que realizaram no Brasil, o que pode ter incentivado Gil-Orozco a abrir uma fábrica de cordas. As cordas produzidas pela Orosco E̊ Blanes eram feitas para os mais diversos fins (CANOVAS, 2009 , p. 289) e eram exportadas para os lugares onde o duo havia realizado recitais. Isto indica que as apresentaçóes também serviram para o estabelecimento de uma rede comercial que, cultivada pelo violonista espanhol, permitiu maiores chances de sucesso em seus empreendimentos em São Paulo. Gil-Orozco costumava ainda apresentar-se em eventos beneficentes, o que reforça a tese da criação de uma rede de relacionamentos que iria alimentar as diversas atividades desenvolvidas pelo músico na cidade.

Em 1906, Gil-Orozco apresentou-se no Salão Steinway, importante sala de concertos da $\operatorname{cidade}^{20}$, ao lado de vários professores e músicos influentes, o que demonstra não somente sua inserção no cenário cultural local, mas, ainda, aponta para uma diversificação do papel social do violão, comumente apontado como marginalizado, e cujo cultivo estaria confinado às classes mais baixas da sociedade brasileira:

Realizou-se no Salão Steinway o concerto do provecto guitarrista espanhol Gil-Orozco, com o concurso valioso da distinta pianista Exma. Sra. d. Elvira Guimarães da Fonseca, do Sr. Alberto Baltar e dos abalizados professores Chiafarelli, G. Bastiani e G. Rochi. [...] Ao Sr. Gil-Orozco couberam, como era natural, as honras da noite. Tocou com admirável nitidez e fino gosto todos os trechos que lhe competiam no programa. Por vezes entusiasmou o auditório que o aplaudia calorosamente, com especialidade nos Cantos da Andaluzia, de Arcas e no Preludio e Minuetto de Tárrega, sendo bisado o último tempo ${ }^{21}$.

\footnotetext{
${ }^{18}$ Ver mais sobre o assunto em: BARBIERI, Patrizio. Roman and neapolitan gut strings 1550-1950. The Galpin Society Journal, v. 59, p. 147-181, 2006, artigo que versa sobre materiais para cordas utilizadas na Europa e cita a utilização de cânhamo para confecção de cordas para instrumentos musicais na França do século XVIII.

${ }^{19}$ Jornal Correio Paulistano, São Paulo, ano XL, n. 14.289, p. 2, 25 mai. 1903.

${ }^{20}$ O Salão Steinway foi incorporado ao Conservatório Dramático e Musical, que iniciou suas atividades em 1906, passando a ser a sala de concertos do Conservatório.

${ }^{21}$ Jornal Correio Paulistano, São Paulo, ano XLVIII, n. 15536, p. 3, 18 nov. 1906.
} 
Conhecemos três composiçóes do violonista espanhol: Recuerdo de Pernambuco; Gavota e Maria (Marzurca). As três peças encontram-se editadas pela Biblioteca Daniel Fortea, de Madrid²2, sendo que um manuscrito da Gavota, datado de 1931, foi encontrado na Coleção Ronoel Simões.

Segundo Ronoel Simões ${ }^{23}$, Gil-Orozco teria lecionado na cidade entre os anos de 1901 e $1908^{24}$, o que, mais uma vez, reforça a hipótese da introdução de princípios da "Escola Tárrega” pelo violonista espanhol. Em 1907, uma notícia sobre a cidade de Campinas inclui o nome do violonista espanhol como um dos professores da cidade de São Paulo, corroborando com a informação de Simões:

CAMPINAS - Uma comissão composta dos srs. maestro Sant'Anna Gomes, Alvaro Ribeiro, Lafayette Egydio e Henrique de Barcellos, vai promover a realização de um grandioso concerto vocal e instrumental no teatro $S$. Carlos, para a próxima época do Carnaval. Para esse certame artístico vão ser convidadas senhoras e senhoritas desta cidade; artistas que aqui têm trabalhado, como sejam d. Elisa Monteiro, Olga Massucci, Romelia Catelli, Malvina Pereira Cauli, Guiomar Novaes; professores Luiz de Padua Machado, barytono C. Silva, Virgilio Angelo, Guido Rocchi, Pattapio Silva, Gil Orosco, etc, e os maestros de Rimini e Antonio Leal ${ }^{25}$.

Ressalta-se, novamente, a circulação do violonista espanhol entre os artistas mais conceituados da historiografia nacional, como a pianista Guiomar Novaes (1894-1979) e o flautista catarinense Patápio Silva (1880-1907), além do violoncelista italiano Guido Rocchi, que participou da criação do Conservatório Dramático e Musical de São Paulo (CANDIDO, 2007, p. 20). Embora não tenhamos encontrado notícias sobre a atividade pedagógica de Gil-Orozco, não podemos descartar a possibilidade de ele ter lecionado o instrumento entre os anos de 1890 e 1899.

\section{Violão e imprensa paulista no séc. XIX}

Na primeira metade do século XIX, as informações em periódicos acerca das práticas musicais do violão em São Paulo $^{26}$ mostram o cultivo entre os escravizados, especialmente no interior do

\footnotetext{
${ }^{22} \mathrm{O}$ catálogo das obras da biblioteca pode ser consultado em: https://bibliotecafortea.com/. Acesso em 29 de jan. de 2020.

${ }^{23}$ Revista Violão e Mestres, São Paulo, ano. II, n. 7, p. 25, 1967.

${ }^{24}$ Em verdade seria até 1907, ano em que Gil-Orozco retorna definitivamente para a Espanha (RODA, 2011, p. 197).

${ }^{25}$ Jornal Correio Paulistano, São Paulo, ano XLVIII, n. 15536, p. 3, 18 de nov. de 1906.

${ }^{26}$ Estas informações foram encontradas em pesquisa realizada nos periódicos do século XIX, na hemeroteca digital da Biblioteca Nacional, disponível em: http://bndigital.bn.gov.br/hemeroteca-digital/. Os dados fazem parte de uma pesquisa de doutorado sobre a consolidação do mundo do violão na cidade de São Paulo, em fase de conclusão (2021).
} 
estado. Diversos anúncios ${ }^{27}$ trazem na descrição sobre os “escravos fugidos” expressôes como: "muito afeiçoado a folguedos, cantador, e tocador de viola"28; "sabe ler e escrever e tocar viola"29; "toca viola com a mão esquerda"30 e "é tocador de viola a esquerda"31.

A partir da década de 1830, surgem as primeiras mençóes sobre compra e venda de instrumentos entre particulares. Em 1841, um anúncio chama a atenção: vende-se "[...] um violão francês com caixa, uma estante para música de gosto muito moderno, com dois castiçais elásticos que se desarmam todos"32, o que sugere que o estudante sabia ler partituras.

O estabelecimento do curso de Direito do Largo de São Francisco (1828) foi determinante para o desenvolvimento cultural e musical da cidade de São Paulo. O primeiro júri celebrado na capital paulista, relatado por um jornal mineiro, trouxe, um ano após a chegada dos estudantes, a notícia de uma serenata realizada pelos estudantes ao término do julgamento:

[...] Na rua, à vista das luminárias que por vários e faustos motivos eram postas, lembraramse tanto Estudantes, como os que não eram, que se deveria procurar uma música regimental para cantar-se um hino. Esta não foi possível reunir-se. Formou-se depois uma dos próprios Estudantes, de flautas, rabecas e violóes: indo primeiro a casa de um, ai foi servido um chá, que não obstante ser preparado à pressa e por tanta gente pode-se chamar de esplendido. Ele foi seguido de danças, valsas $[\ldots]^{33}$.

A primeira menção à circulação de métodos na cidade de São Paulo data de $1854^{34}$, sendo o método anunciado o do italiano Francesco Molino (1768-1847). Em 1860, a Revista Dramática trouxe informação sobre um violonista de nome Giovani Scioppio, “[...] que executa no violão as partes mais difíceis que lhe pedem [...]”35. Outra referência a um violonista apresentando-se na cidade é sobre Clementino Lisboa, engenheiro e violonista amador ${ }^{36}$ residente no Rio de Janeiro. É chamado

\footnotetext{
${ }^{27}$ A grafia dos textos de jornal foi atualizada para a confecção deste artigo, com intuito de tornar a leitura mais fluída.

${ }^{28}$ O Novo Farol Paulistano, São Paulo, ano 06, ed. 454, p. 4, 10 ago. 1836.

${ }^{29}$ O Farol Paulistano, São Paulo, ano 03, ed. 224, p. 4, 27 jun. 1829.

${ }^{30}$ O Farol Paulistano, São Paulo, ano 03, ed. 262, p. 4, 24 out. 1829.

${ }^{31}$ O Farol Paulistano, São Paulo, ano 04, ed. 367, p. 4, 22 jul. 1830.

${ }^{32}$ A Phenix, São Paulo, ano 04, ed. 364, p. 4, 09 out. 1841.

${ }^{33}$ Jornal Astrea, Minas Gerais, n. 383, p. 3-4, 27 jan. 1829.

${ }^{34}$ Correio Paulistano, São Paulo, ano XI, ed. edição n. 82, p. 4, 02 abril 1854. Ressaltamos que 1854 foi também o ano do surgimento do jornal, assim, é possível que o método já circulasse na cidade e que tenha passado a ser anunciado na imprensa com o surgimento do periódico.

${ }^{35}$ Revista Dramática, São Paulo, ano I, vol.3, p. 42, 1860.

${ }^{36}$ Ressalta-se que, neste período amador, não se refere às capacidades e habilidades técnico-musicais, mas sim ao fato de o músico desempenhar outra profissão que garantia seu sustento financeiro.
} 
de “[...] primeiro herói a apresentar o instrumento em versão solista [...]” em artigo publicado na revista $O$ Violão ${ }^{37}$. Lisboa aparece em um sarau na capital paulista, na residência do Sr. Sizenando $\mathrm{Nabuco}^{38}$, no ano de 1864 :

O hábil artista Sr. Lisboa foi o rei da festa, extraindo das cordas do seu violão os mais harmoniosos e suaves sons que jamais violão algum poderá imitar. O eminente poeta revelou uma alma elevada e um superior talento. A Norma e a Traviata, esses dois suspiros supremos da deusa esplendorosa da música, foram interpretados e executados com sentimento que ia direto à alma dos artistas, enleando a todos em uma mesma rede de vaporosos amores ${ }^{39}$.

\section{Em 1878, uma apresentação beneficente na Escola Americana ${ }^{40}$ trouxe a notícia da participação}

de um duo de violóes:

Concerto no Colégio Americano, promovido por seus diretores, srs. Chamberlain e J. B. Howell, em benefício das vítimas da seca no norte do Império ${ }^{41}$. Dentre os números apresentados está O canto da coruja, [famosa polca de autoria de Emílio do Lago] executado a dois violôes pelos amadores Theotônio Gonçalves Correa e Manoel Maximiano de Toledo $^{42}$ (c. 1833-c. 1890) ${ }^{43}$.

Theotônio Gonçalves Correa (c. 1860 - c. 1935) foi um violonista que participou do início da

\footnotetext{
${ }^{37}$ Revista O Violão, Rio de Janeiro, ano 01, número 01, p. 9, dez. de 1928.

${ }^{38}$ Sinezando, irmão do político e diplomata Joaquim Nabuco, estudante da Academia de Direito. O Teatro São José encenou, na inauguração (07 de setembro de 1964), uma peça de sua autoria, A Túnica de Nessus (TOLEDO, 2012, p. 341). Ver mais sobre o sarau e sobre Sinezando Barreto Nabuco de Araújo em: REZENDE, Carlos Penteado de. Tradiçốes musicais da Faculdade de Direito de São Paulo. Ed. ilustrada, comemorativa do IV centenário de São Paulo. São Paulo: Edição Saraiva, 1954, p. 205.

${ }^{39}$ Correio Paulistano, São Paulo, ano XI, ed. 2393, p.2, 11 de maio de 1864, p. 244.

${ }^{40}$ Fundada em 1870, pela esposa do reverendo Chamberlain, Mary Annesley Chamberlain, em sua residência, para atender as crianças não católicas, a escola mudou-se (1876) para a Rua São João, número 70, esquina com a Rua Ipiranga, onde funcionou por 42 anos e recebeu a visita do Imperador D. Pedro II em 1878. AMARAL, Antônio Barreto do. Dicionário de história de São Paulo. São Paulo: Imprensa Oficial, 2006.

${ }^{41}$ A Grande Seca, no nordeste brasileiro (1877-1879), cuja região mais afetada foi a província do Ceará, foram três anos sem chuvas, tendo sido o fenômeno mais devastador da seca brasileira, responsável pela morte de mais de 400.000 pessoas. Mais de 180 mil nordestinos migraram para diversas partes do país. Ver mais sobre em: MOURA, Denise Ap. Soares de. Andantes de novos rumos: a vinda de migrantes cearenses para fazendas de café Paulistas em 1878. Revista brasileira de bistória, v. 17, n. 34, p. 119-132, 1997.

${ }^{42}$ Foi exímio na arte de tocar violão, e conhecido taquígrafo, por muitos anos à frente deste serviço nas assembleias provinciais de S. Paulo. Informação encontrada no site da Genealogie Petroucic, disponível em: https://www.genealogieonline.nl/en/petroucic-genealogy/I307267.php, Acesso em 09 abr. 2020.

${ }^{43}$ Diário de S. Paulo, São Paulo, ano XIII, n. 3631, p. 2, 27 jan. 1878.
} 
radiofonia e da fonografia em fins da década de $1920^{44}$. Trata-se provavelmente do primeiro violonista a publicar músicas em São Paulo (1882). Embora não tenhamos localizado até o momento a partitura do tango paulista referido abaixo, foi possível localizar outra peça, a Recordação Saudosa ${ }^{45}$, editada pela casa L. Levy $\Xi^{2} \operatorname{Irmãos}(\mathrm{s} / \mathrm{d})$, com a indicação de mazurca sentimental. A partitura foi editada em versão para piano e traz a notação: “[...] do mesmo autor de Pery, Tango, e Dodonquinha, Polka [...]”, o que indica o sucesso das músicas que serviam de chamariz para a edição da nova obra.

PERY. Publicou ontem o sr. Theotônio Gonçalves Correa uma composição musical com este título. Pery é um tango paulista de rara beleza; ouvimo-lo executado ao piano e ao violão, e principalmente neste último instrumento, achamos deliciosa a música do Sr. Theotônio que, além de revelar-se agora inspirado compositor, é na opinião de quantos o tem ouvido, exímio, não só o primeiro violonista de $S$. Paulo ${ }^{46}$.

As três peças de Theotônio publicadas pela Casa Levy; o testemunho do articulista que ouviu o tango diversas vezes para violão e o duo de Manuel Maximiliano e Theotônio são alguns dos resquícios da prática do instrumento do último quartel do século XIX, que seguramente merecem maior atenção. Em texto publicado no final da década de 1910, um autor anônimo evocou, com nostalgia, o violão cultivado na cidade no final do século XIX, corroborando com a impressão de que havia uma tradição "pré-moderna” ${ }^{47}$, cujo herdeiro, ainda segundo o autor, seria Américo Jacomino:

Certo, o leitor não chegou a conhecer o ultra-violonista da Pauliceia desse tempo, o Venâncio, que era mestre nesse instrumento e que, quando tocava a sua predileta - o Lasquenet (sic) - se esquecia de sí e dos outros e perdia a noção da realidade, fazendo roncar o bordão metálico ou fazendo gargalhar a prima, numa risada estridente, de comoção nervosa; e talvez mesmo nem chegasse a ouvir o Theotonio, outro violonista de valia, que no S. Paulo de antanho fez época, sendo extraordinário, sobretudo, no "Canto da Coruja", que a gente ouvia e tinha a ilusão auditiva de que estava ouvindo aquele agoureiro pássaro noturno, em noite alta, a fazer tremer de medo os supersticiosos, com seu lamentoso gemido. Onde está o violão desse tempo? Hoje em dia só conhecemos o Americo Jacomino, apelidado de "Canhoto", que ainda mantém algo da tradição desses violonistas [...]. ${ }^{48}$

\footnotetext{
${ }^{44}$ Juntamente com João Avelino Camargo e José Martins Duarte de Melo. É o primeiro trio de violóes brasileiro de que temos conhecimento. Registrou cinco músicas pelo selo Brunswick: a gavota Iole e o choro Sabãozinho, ambos de autoria de Avelino Camargo (1930); os choros Cadê o Cruzeiro e Bancando o Nazareth, de Theotônio Corrêa, e Negrinha de filó, de Avelino Camargo (1929). Cadê o Cruzeiro (cuja partitura tem como título Cruzeiro, sendo identificada como maxixe) e Iole foram editadas para violão solo e arranjadas para três violóes para as gravaçôes fonográficas, apresentações em público e em programas da radiofonia.

${ }^{45}$ A partitura para piano (s/d, c. 1885) foi adquirida no site de compra e venda do Mercado Livre, em 2018.

${ }^{46}$ Correio Paulistano, São Paulo, ano XXIX, n. 7850, p. 2, 02 dez. 1882.

${ }^{47}$ Pré-moderna em relação ao já abordado violão moderno de Arcas, Tárrega e Torres.

${ }^{48}$ Correio Paulistano, São Paulo, ano LVII, n. 20092, p. 3, 12 jun. 1919.
} 


\section{O duo Toboso-Gil-Orozco na imprensa paulistana: as críticas de Alexandre Levy}

Alexandre Levy (1864-1892) foi um compositor, pianista, regente e crítico musical paulista. Seus pais, o clarinetista francês Henrique Luís Levy e a suíça Anne Marie Teodoreth abriram na cidade a Casa Levy, loja de pianos e partituras. Durante todo o final do século XIX, o estabelecimento permaneceu como importante ponto de encontro de músicos paulistanos. Em 1887, Alexandre Levy foi estudar em Milão, onde conheceu os professores Cerare Dominicet (1821 - 1888) e Alberto Giannini (1842 - 1903), e Paris, onde teve aulas de harmonia e contraponto com Émile Durand (1830 - 1903), mestre de Claude Debussy (1850 - 1918), e Vizenzo Ferroni (1958 - 1934). Ao voltar, retomou as atividades artísticas, organizando concertos e passou a escrever crítica musical no jornal Correio Paulistano, assinando artigos com o pseudônimo de Figarote ${ }^{49}$.

O pesquisador Said Tuma notou algumas características de Alexandre Levy, no campo da crítica musical:

[...] Aqui também se observam indícios de sua modernidade. Ao adotar comumente uma atitude de comedimento em relação às questóes musicais — optando muitas vezes por um tom humorístico nos seus escritos - além de prestigiar, na sua reflexão crítica, na maior parte das vezes, aspectos técnicos da execução musical, Levy vai se diferenciar dos demais articulistas da capital. Não obstante manifestasse em seus artigos, por vezes, algo da ótica civilizatória presente nas concepçôes modernizadoras da elite paulista, com seu comedimento e humor, Levy consegue atenuar essa perspectiva, revelando-se um articulista mais discreto e, por que não dizer, mais moderno (TUMA, 2008, p. 137).

Portanto, as críticas de Levy para o jornal Correio Paulistano estão no contexto dos anseios civilizatórios da elite paulistana e coadunam com o processo modernizador suscitado pelo advento da república (1889). Levy recebia os artistas nos salóes da Casa Levy para os "concertos para imprensa": os músicos faziam um recital privado para a imprensa local dias antes do concerto público (o que permaneceu uma praxe também no século XX). Assim, forneciam material para que os jornalistas escrevessem, convocando o público a assistir ao concerto previamente aprovado por pessoas influentes da cidade. Alexandre Levy, portanto, fomentava a atividade dos concertos, realizando na loja de sua família as récitas para imprensa e, posteriormente, escrevia como Figarote, o crítico musical.

49 As informações foram retiradas da Enciclopedia do Itaú Cultural, disponível em: http://enciclopedia.itaucultural.org.br/pessoa593911/alexandre-levy. Acesso em 29 de jan. de 2020. 
Agradecia a Casa Levy e convocava os leitores a assistir ao concerto. Depois do concerto, escrevia mais um texto, dessa vez a crítica sobre o concerto público.

Longe de representar algum tipo de esquizofrenia, esta postura refletia a modernidade apontada por Tuma. Afinado com princípios da chamada "geração de 1870" missão de atualizar o Brasil, colocá-lo dentro do “concerto das nações”, integrando-o a uma modernidade internacional. Era necessário, para modernizar, promover, pela ação direta de intelectuais, a "elevação do nível cultural população". Neste sentido, é interessante notar que, ao contrário dos críticos da imprensa das primeiras décadas do século XX, Levy não desqualificou o violão ao elogiar o desempenho dos músicos espanhóis. Ao contrário, o crítico demonstrou conhecimento das reais possibilidades do instrumento.

Sobre a performance musical dos dois violonistas, Levy apontou: “[...] não são imerecidos os elogios que os dois artistas receberam tanto da imprensa fluminense como da santista, pois são eles dois violonistas de mão cheia e tiram dos instrumentos, especialmente fabricados segundo planos seus [...]”; “[...] tiram os dois artistas os efeitos mais perfeitos que é dado a um violonista tirar de seu instrumento [...]”; “[...] Sr. Toboso tocou só e com grande maestria um pot-pourri de árias nacionais espanholas onde ouvimos a jota, a seguidilha e outras danças características do país de lãs niñas guapas [...]" e “[...] sendo digno de nota a correção com que modulam as tonalidades, a justeza, e a afinação irrepreensível dos instrumentos [...]”.

Sobre a recepção da plateia, o crítico notou: "Foi mais um triunfo para os simpáticos e guapos muchachos que souberam fazer com que o público se conservasse em silêncio e atencioso durante as peças que tocaram, sendo sempre ao finalizá-las, cobertos de calorosos e entusiásticos aplausos [...]”. Ainda sobre a assistência ao concerto, Levy sugeriu que realizem mais concertos na capital:

Visto a boa concorrência que tiveram na noite de anteontem e como ainda grande parte da nossa capital não ouviu estes dois artistas sui generis, será medida acertada resolverem dar mais um ou mesmo dois concertos para que os paulistas fiquem sabendo quanto vale um Jota e um Zapatiado executado pelos violóes mágicos dos srs. Toboso e Orozco ${ }^{51}$.

\footnotetext{
${ }^{50}$ No período de crise do império e de grandes transformações no país, uma série de grupos e atores sociais, que viviam e incorporavam esse período sob diferentes perspectivas, começaram a gestar - direta e indiretamente, consciente e inconscientemente, por meio do cruzamento de práticas e discursos bastante heterogêneos entre si - um novo projeto de país, um novo projeto de sociedade: um projeto de "Civilização" inspirado na realidade que despontava na Europa. Dentro desse contexto, a chamada geração intelectual de 1870 assumiu a missão de formular análises sobre o país, com o objetivo de traçar o caminho que constituiria o Brasil como um país civilizado (COUTO, 2016, p. 1).

${ }^{51}$ Correio Paulistano, São Paulo, ano XXXVI, n. 10121, p. 2, 04 jun. 1890.
} 
Acerca do violão de onze cordas, o crítico notou: “[...] a forma desses instrumentos é muito maior e mais bojuda que os nossos conhecidos: possuem onze cordas, sendo oito sobre o espelho e três soltas, abrangendo, portanto uma extensão de três ou quatros oitavas, se não nos falha a memória [...]”. Também o repertório que o duo executava foi descrito por Figarote:

[...] destacamos a valsa Les Sirenes, de Thomé [tratando-se provavelmente da valsa para piano La Sirene, do compositor francês Francis Thome (1850-1909)]; o Minueto de Balzoni [tratando-se provavelmente de Giovanni Bolzoni (1841-1919)], a Valsa em lá menor, de Chopin, uma fantasia sobre trechos das óperas Baile de máscaras [Giuseppe Verdi (18131901)], o Jota de las Ratas da Gran Via, [da zarzuela Gran Via, do compositor Federico Chueca (1846-1908)], árias das óperas O Trovador, de Verdi, e Poliuto [de Domenico Gaetano Maria Donizetti (1797-1848)] e Canção Árabe Maraima $a^{52}$ ou Capucho Hespanbol Moraima. ${ }^{53}$.

\section{Conclusão}

Embora estejamos ainda no início do processo de descortinar a produção violonística do século XIX no país, os dados localizados até o momento parecem indicar que a narrativa de instrumento marginalizado, de poucos recursos, salvo quando manipulado por algum virtuose extraordinário, é um construto do século XX, e representa apenas uma das narrativas possíveis sobre o instrumento que, de forma transversal, esteve presente nas mais diversas manifestaçóes culturais da sociedade brasileira.

A julgar pelos periódicos do século XIX, o violão dividia repertório e práticas musicais com outros instrumentos. Frases como: “[...] Pery é um tango paulista de rara beleza; ouvimo-lo executado ao piano e ao violão, e principalmente neste último instrumento [...]”; "[...] tiram os dois artistas os efeitos mais perfeitos que é dado a um violonista tirar de seu instrumento [...]” ou "[...] a forma desses instrumentos é muito maior e mais bojuda que os nossos conhecidos [...]", denotam familiaridade e nenhum espanto para com o instrumento, como o que os violonistas estrangeiros do início do século XX causaram na imprensa, e que pode ser exemplificado em frases como a do poeta Manuel Bandeira $^{54}$ : "Ele foi, porém [o violão], reabilitado pela visita que recebemos de dois estrangeiros, os

\footnotetext{
${ }^{52}$ Provavelmente uma canção sobre Morayma, última rainha moura do reino de Granada, esposa do Rei Boabdil (c. 1460c. 1533), que foi fonte de inspiração para diversos escritores e poetas.

${ }^{53}$ Correio Paulistano, São Paulo, ano XXXVI, n. 10121, p. 2, 04 jun. 1890.

${ }^{54}$ BANDEIRA, Manoel. A Literatura do Violão. Ariel Revista de Cultura Musical, n. 13, p. 463-468, São Paulo, 1924.
} 
quais vieram revelar aos nossos amadores todos os recursos e a verdadeira escola dos grandes virtuoses de Espanha. Refiro-me a Agostinho Barrios ${ }^{55}$ e Josefina Robledo [...]”. Ou, ainda, em Mário de Andrade: "Em relação a certos instrumentos que nem o violão, abandonados durante um certo tempo ao povo, quando surge um virtuose deles, isso é fruto de mero acaso $[. .].]^{\prime 56}$.

Verificamos que o repertório praticado por estes músicos seguia o movimento mais amplo do teatro musicado, segundo a tendência europeia, alternando trechos de óperas, baladas de comédias de costumes, canções folclóricas e danças de salão. Dessa forma, o violão estava inserido no contexto mais amplo do movimento musical da cidade.

Notamos ainda que, quanto mais as tecnologias avançam, mais ferramentas elas nos fornecem para que aumentemos nosso conhecimento sobre o passado, possibilitando-nos retroceder na linha do tempo em busca de informações sobre as sonoridades e as práticas musicais de outrora. Assim, a digitalização dos periódicos, os sistemas de busca cada vez mais sensíveis e a democratização do acesso via rede mundial de computadores têm descortinado a presença do violão em contextos que não nos era possível vislumbrar anteriormente. Servindo como uma espécie de guia, as informações sobre as práticas e repertórios nos permitem rastrear em acervos públicos e particulares a produção realizada no século XIX e redimensionar o alcance de sua difusão. Trata-se de um momento novo para a musicologia do instrumento, de um campo repleto de possibilidades para inúmeras pesquisas, que permitirão a reconstrução da historiografia do instrumento, retrocedendo em pelo menos meio século o que julgávamos ser o início da tradição solista do violão no país ${ }^{57}$. Além disto, abre-se a possibilidade de ampliação substancial do repertório para o instrumento.

\footnotetext{
${ }^{55}$ Agustin Barrios, violonista paraguaio, foi decisivo para a difusão do violão na América do Sul. Mais informaçôes disponíveis em: DELVIZIO, Cyro. Agustín Barrios no Pais do Sonbo: A incrível jornada de um violonista paraguaio pelo Brasil. Rio de Janeiro: Edição do autor, 2015.

${ }^{56}$ Diário Nacional, São Paulo, ano III, n. 705, p. 7, 15 out. 1929.

${ }^{57}$ Há cerca de três anos, julgávamos ser de 1904 a mais antiga peça para violão, a inacabada Valsa de Concerto no2, de VillaLobos, sendo que a já citada publicação, O Guitarrista Moderno, data de 1857, mas há anúncios de partituras desde 1810 em periódicos nacionais.
} 


\section{REFERÊNCIAS}

\section{Referências bibliográficas}

AMARAL, Antônio Barreto do. Dicionário de história de São Paulo. São Paulo: Imprensa Oficial, 2006.

AMORIM, Humberto. Idiomatismos na produção para violão de Melchior Cortez (1882-1947). DEBATES-Cadernos do Programa de Pós-Graduação em Música. Rio de Janeiro, n. 21, p. 43-79, nov. 2018.

ANTUNES, Gilson Uehara. Americo Jacomino Canhoto e o desenvolvimento da arte solistica do violão em São Paulo. 2002. Dissertação (Mestrado em Artes) - Escola de Comunicações e Artes, Universidade de São Paulo, São Paulo, 2002.

BANDEIRA, Manoel. A Literatura do Violão. Revista Ariel. São Paulo, n. 13, p. 463-468, 1924.

BARBIERI, Patrizio. Roman and neapolitan gut strings 1550-1950. The Galpin Society Journal, v. 59, p. 147-181, 2006.

BARTOLONI, Giacomo. O violão na cidade de São Paulo no periodo de 1900 a 1950. 1995. Dissertação (Mestrado em Música) - Instituto de Artes, Universidade Estadual Paulista, São Paulo, 1995.

BARTOLONI, Giacomo. Violão: a imagem que fez escola. São Paulo 1900-1960. 2000. Tese (Doutorado em História) - Faculdade de Ciências, História e Letras de Assis, Assis, 2000.

CANDIDO, Antonio. Teresina e etc. São Paulo: Cosac Naif, 2007.

CANOVAS, Marilia Dalva Klaumann. Imigrantes espanhóis na pauliceia: trabalho e sociabilidade urbana, 1890-1922. São Paulo: Edusp, 2009.

COUTO, Bruno Gontyjo do. O debate sobre meio e raça na geração intelectual de 1870: a construção de um projeto de civilização para o Brasil. Em Tese, v. 13, n. 1, p. 94-119, 2016.

DELVIZIO, Cyro. Agustin Barrios no Pais do Sonho: A incrível jornada de um violonista paraguaio pelo Brasil. Rio de Janeiro: Edição do autor, 2015.

GALINDO, Miguel Antonio. Enciclopedia de la Guitarra. Madrid: VP Music Media, 2011.

GONÇALVES, Leandro Márcio. O processo de difusão do violão clássico no Brasil através da "Escola de Tárrega" entre 1916 e 1960. 2015. Dissertação (Mestrado em Música) - Universidade de Évora, Évora, 2015.

HERRERA, Francisco. Enciclopedia de la Guitarra, segunda edición corregida y aumentada. 
Valencia: Editorial Piles, 2011.

MOURA, Denise Ap. Soares de. Andantes de novos rumos: a vinda de migrantes cearenses para fazendas de café Paulistas em 1878. Revista brasileira de história, v. 17, n. 34, p. 119-132, 1997.

OROSCO, Maurício T. S. O compositor Isaias Savio e sua obra para violão. 2001. Dissertação (Mestrado em Musicologia) - Escola de Comunicação e Artes, Universidade de São Paulo, São Paulo, 2001.

PICHERZKY, Andrea Paula. Armando Neves: choro no violão paulista. 2004. Dissertação (Mestrado em Musicologia) - Instituto de Artes, Universidade Estadual Paulista, São Paulo, 2004.

REZENDE, Carlos Penteado de. Tradiçôes musicais da Faculdade de Direito de São Paulo. Ed. ilustrada, comemorativa do IV centenário de São Paulo. São Paulo: Edição Saraiva, 1954.

RICOEUR, Paul. A memória, a história, o esquecimento. Trad. Alain François. Campinas: Editora da Unicamp, 2007.

RODA, Luis Gil-Orozco. El Guitarrista Gil-Orozco, el artista, el hombre y su tiempo. Requena: edición del autor, 2011.

TABORDA, Marcia. Violão e identidade nacional. Rio de Janeiro: Editora José Olympio, 2011.

TORRES, Norberto. La guitarra en la prensa de Sevilla y Almería en las dos épocas de Julián Arcas y Antonio de Torres. Sinfonía Virtual: Revista de Música Clásica y Reflexión Musical, n. 36, p. 1-43, 2019.

TUMA, Said. O Nacional e o Popular na Música de Alexandre Levy: Bases de um Projeto de Modernidade. 2008. Dissertação (Mestrado em Artes) - Escola de Comunicações e Artes, Universidade de São Paulo, São Paulo, 2008.

\section{Periódicos históricos consultados}

A Phenix, São Paulo, ano 04, ed. 364, p. 4, 09 out. 1841.

Correio Paulistano, São Paulo, ano XI, ed. edição n. 82, p. 4, 02 abril 1854.

Correio Paulistano, São Paulo, ano XI, ed. 2393, p. 2, 11 de maio de 1864.

Correio Paulistano, São Paulo, ano XXIX, n. 7850, p. 2, 02 dez. 1882.

Correio Paulistano, São Paulo, ano XXXVI, n. 10121, p. 2, 04 jun. 1890.

Correio Paulistano, São Paulo, ano XXXVII, ed. 10256, p. 1, 09 nov. 1890.

Correio Paulistano, São Paulo, ano XL, n. 14.289, p. 2, 25 mai. 1903.

Correio Paulistano, São Paulo, ano XLVIII, n. 15536, p. 3, 18 nov. 1906. 
Correio Paulistano, São Paulo, ano LVII, n. 20092, p. 3, 12 jun. 1919.

Diário de S. Paulo, São Paulo, ano XIII, n. 3631, p. 2, 27 jan. 1878.

Diário Nacional, São Paulo, ano III, n. 705, p. 7, 15 out. 1929.

Jornal Astrea, Minas Gerais, n. 383, p. 3-4, 27 jan. 1829.

O Commercio de São Paulo, São Paulo, ano VIII, n. 2310, p. 3, 24 ago. 1901.

O Commercio de S. Paulo, São Paulo, ano XII, n. 3649, p. 4, 01 mai. 1904.

O Farol Paulistano, São Paulo, ano 03, ed. 224, p. 4, 27 jun. 1829.

O Farol Paulistano, São Paulo, ano 03, ed. 262, p. 4, 24 out. 1829.

O Farol Paulistano, São Paulo, ano 04, ed. 367, p. 4, 22 jul. 1830.

O Novo Farol Paulistano, São Paulo, ano 06, ed. 454, p. 4, 10 ago. 1836.

O Violão, Rio de Janeiro, ano 01, número 01, p. 9, dez. 1928.

Revista Dramática, São Paulo, ano I, vol.3, p. 42, 1860.

Violão e Mestres, São Paulo, Giannini S.A., ano II, n.o 07, p. 25, 1967.

Violão e Mestres. São Paulo: Giannini S.A., ano II, no 9, p. 51, 1968.

\section{SOBRE A AUTORA}

Flavia Prando é violonista, bacharel em Música pela Universidade Estadual Paulista Júlio de Mesquita Filho (UNESP), é mestre em Artes pela Escola de Comunicação e Artes da Universidade de São Paulo (USP) e doutoranda em Música na mesma instituição, sob orientação da Prof. - Dr.․ㅡ Flávia Camargo Toni. É Pesquisadora em Ciências Sociais e Humanas no Centro de Pesquisa e Formação do Sesc/SP. ORCID: http://orcid.org/0000-0001-6542-2624. E-mail: flaviaprando@usp.br 